\title{
Determination of S-amlodipine in Human Plasma Using Tizanidine as Internal Standard by Lc/Ms/Ms Method
}

\section{Rajesh Dhiman ${ }^{1}$, Vijaya Durga² and Konsam Hamlet Meetei ${ }^{3}$}

${ }^{1}$ Micro Therapeutic Research Labs Pvt. Ltd. Chennai, India

${ }^{2}$ Sir C.R. Reddy College of Pharmaceutical Sciences Eluru, Andhra Pradesh, India

${ }^{3} R V S$ College of Pharmaceutical Sciences Coimbatore, Tamilnadu, India

\begin{abstract}
High performance liquid chromatographic tandom mass spectrometric method for the estimation of S-amlodipine in human plasma has been developed and validated using Tizanidine as internal standard. Sample process was accomplished by Liquid-Liquid Extraction technique. The processed sample was chromatographed and analysed on Phenomenex, Lux 3u Cellulose-2 $(150 \times 4.6) \mathrm{mm}$ column using mobile phase $[0.1 \%$ formic acid in water and Acetonitrile $(50: 50 \% \mathrm{v} / \mathrm{v})]$. S-amlodipine was chromatographed and analysed by MS detector. Amlodipine has two basic moiety (one primary and one secondary amino) so it shows $\mathrm{pKa}=9.45$ with two ester linkages and one ether linkage, so it is highly lipid soluble $(\log \mathrm{P}=2.22)$ whereas Tizanidine has two secondary amino and three tertiary amino groups, so it shows $\mathrm{pKa}=7.49$. Primary amine $-\mathrm{NH}_{2}$ is aliphatic in nature in amlodipine and secondary amine $-\mathrm{NH}$ is in ring so it has less action of basicity. Tizanidine has secondary amine $-\mathrm{NH}$ is in chain which predominates the basicity $(\mathrm{pKa}=7.49)$ and other secondary and tertiary amines are in ring so they show less action with formic acid/ACN mobile phase. Formic acid ionizes (primary amino) $-\mathrm{NH}_{2}$ part, then (secondary amino) $-\mathrm{NH}$ part and then (tertiary amino) $=\mathrm{N}$ part. So amlodipine elutes 1 st then tizanidine comes out. LogP of amlodipine is 2.22 and for tizanidine it is 1.4 , so due to Formic acid-water/CAN mobile phase Amlodipine has higher retention time than tizanidine and comparison Rt. The analytical method described is valid the determination of S-amlodipine (over a range of $0.77 \mathrm{ng} / \mathrm{ml}$ to $50.98 \mathrm{ng} / \mathrm{ml}$ ) using Tizanidine as internal standard in human plasma. Signals from the detector were captured in a computer and processed using Analyst software. This validation report provides results of various validation parameters.
\end{abstract}

Keywords: S-amlodipine; Tizanidine; Internal standard; LC/MS/MS; Validation

\section{Introduction}

Levamlodipine (INN), also known as Levoamlodipine or $\mathrm{S}$-amlodipine is a pharmacologically active enantiomer of Amlodipine. Amlodipine belongs to the dihydropyridine group of calcium channel blocker used as an antihypertensive and antianginal agent. Amlodipine blocks the transmembrane influx of calcium into the vascular and cardiac smooth muscles resulting in vasodilation and hence a fall in blood pressure. Levamlodipine is an allosteric modulator and acts on the L- type of calcium channels. Receptor binding studies have shown that out of the two forms only the $(S)$ enantiomer of Amlodipine binds to and blocks L-type calcium channels whereas the $(R)$ enantiomer has no activity on these channels. Oral administration of Levamlodipine (2.5 $\mathrm{mg})$ as a single dose gives maximum plasma concentration $\left(\mathrm{C}_{\max }\right)$ of 8.3 to $9.3 \mathrm{ng} / \mathrm{ml}$ in 2 to $3 \mathrm{hrs}\left(\mathrm{T}_{\max }\right)$. It is extensively (about $90 \%)$ converted to inactive metabolites via hepatic metabolism with $10 \%$ of the parent compound and $60 \%$ of the metabolites excreted in the urine. Levamlodipine shows approximately $93 \%$ plasma protein binding in hypertensive patients. The mean AUC0t value ( $\mathrm{t}=48 \mathrm{hrs}$ ) of Levamlodipine tablets $(2.5 \mathrm{mg})$ is $95 \pm 14 \mathrm{ng} \mathrm{hr} / \mathrm{ml}$. The plasma elimination half-life of Levamlodipine has been found to be $31 \pm 13 \mathrm{hrs}$. Different methods for the determination of Amlodipine in biological fluids, such as gas chromatography (GC) [1] or liquid chromatography (LC) [2-4] or mass spectrometric analysis [5-7], previously reported methods [8-12] either had long retention time (10-15min) or suffered from low sensitivity and in some cases required large sample injection volumes. Hence the main objective of this work was to develop a simple, sensitive, rapid and reliable mass spectrometry method for the quantification of S-amlodipine in human plasma. Only limited methods have been reported in the HPLC and GC. The objective of the work was to develop and validate LC-MS/MS method for quantification in Human Plasma. The method shows more sensitive limit of detection and Limit of Quantification is very less to the previous reported methods.

\section{Materials and Methods}

\section{Chemicals and reagents}

S-amlodipine [13] (Figure 1) and Tizanidine (IS) [14] (Figure 2) working standards were used. HPLC grade Acetronitrile and<smiles>CCOC(=O)C1=C(COCCN)NC(C)=C(C(=O)OC)[C@H]1c1ccccc1Cl</smiles>

Figure 1: Structure of S-amlodipine.

*Corresponding author: Rajesh Dhiman, Research Associate, Micro Therapeutic Research Labs Pvt. Ltd, Chennai, India, Tel: +09817893170; Email: rajdhiman60@gmail.com

Received April 28, 2015; Accepted May 15, 2015; Published May 18, 2015

Citation: Dhiman R, Durga V, Meetei KH (2015) Determination of S-amlodipine in Human Plasma Using Tizanidine as Internal Standard by Lc/Ms/Ms Method. J Bioanal Biomed 7: 091-096. doi:10.4172/1948-593X.1000130

Copyright: $\odot 2015$ Dhiman R, et al. This is an open-access article distributed unde the terms of the Creative Commons Attribution License, which permits unrestricted use, distribution, and reproduction in any medium, provided the original author and source are credited. 
Methanol were manufactured by Qualigens Fine Chemicals, Formic acid AR grade manufactured by S.D. Fine chemicals, Water HPLC grade from Milli-Q RO system was used throughout the analysis. Diluent (50\% methanol in water) and extraction solvent diethyl ether were used.

\section{Chromatographic conditions}

The chromatography was performed on an ACQUITYTM UPLC system (Waters Corp, USA) $[15,16]$ with cooling auto sampler and column oven enabling temperature control of the analytical column. Phenomenex, Lux $3 u$ Cellulose- $2(150 \times 4.6) \mathrm{mm}$ column was employed. The column temperature was maintained at $45^{\circ} \mathrm{C}$ and chromatographic separations were achieved with isocratic elution using a mobile phase composed of $[0.1 \%$ formic acid in water, Acetonitrile (50:50\% v/v)]. The flow rate was set at $0.4 \mathrm{ml} / \mathrm{min}$, run time was 5.5 minutes and retention time for S-amlodipine and Tizanidine were $3.9 \mathrm{~min}$. and $3.4 \mathrm{~min}$ respectively. The auto sampler was conditioned at $4^{\circ} \mathrm{C}$ and the injection volume was $10 \mu \mathrm{l}$ using Auto sampler mode for sample injection.

\section{Compound Setting}

Ion source ESI Positive mode, Ion spray voltage at $4.5 \mathrm{kV}$, temperature at $500^{\circ} \mathrm{C}$, curtain gas at $6 \mathrm{~L} / \mathrm{min}$, nebulizer gas at $12(\mathrm{psi})$ and collision gas at $6 \mathrm{~L} / \mathrm{min}$ were set. The Parent mass For S-amlodipine (409.3) $\mathrm{m} / \mathrm{z}$ and Tizanidine $(254.2) \mathrm{m} / \mathrm{z}$, Product mass S-amlodipine (238.1) $\mathrm{m} / \mathrm{z}$ and Tizanidine (44.1) $\mathrm{m} / \mathrm{z}$, and collision energy was $15 \mathrm{eV}$ and $46 \mathrm{eV}$ respectively.

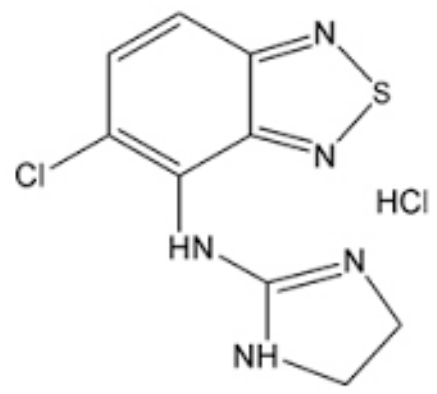

Figure 2: Structure of Tizanidine.

\section{Plasma sample extraction procedure}

$50 \mu \mathrm{l}(1000 \mathrm{ng} / \mathrm{ml})$ of internal standard solution was admixed with $0.500 \mathrm{ml}$ of sample in a RIA-vials and vortexed for 1 minute, 2.5 $\mathrm{ml}$ of extraction solvent was added. The content was vertexed for 10 minutes at $14000 \mathrm{rpm} ; 1.8 \mathrm{ml}$ organic layer transferred into RIA vials and evaporated upto dryness at $35^{\circ} \mathrm{C}$ under a stream of nitrogen gas. The dried residue was reconstituted with $0.150 \mathrm{ml}$ of diluent and vortex for 60 minutes. Samples were injected into the LC-MS/MS system for analysis

\section{Validation parameters}

Blank screening, selectivity, linearity, accuracy, precision, stability (freeze thaw, bench top, long term, auto sampler, stock solution at RT and RF) Each batch of spiked plasma samples includes one complete calibration curve (consisting of one blank plasma, one blank plasma with internal standard and eight different non-zero concentration samples, six replicates quality control samples includes six replicate quality control samples LLOQ,LQC,MQC and HQC), except bench top, freeze thaw stability, long term stability, auto sampler stability and dilution integrity in which four replicate quality control samples were used. Quality control samples for S-amlodipine prepared by using CPD as an anticoagulant and stored at a temperature below $-20^{\circ} \mathrm{C}$ (deep freezer), protected from light with concentrations taken as LLOQ $(0.79$ $\mathrm{ng} / \mathrm{ml}$ ) (Figure 3), LQC (2.13 ng/ml) (Figure 4), MQC (22.62 ng/ml) (Figure 5) and HQC (45.25 ng/ml) (Figure 6)

\section{Standardization and Calculation}

The chromatographic data were acquired and processed using computer based Analyst software. The best-fit lines using weighting factor ( $1 /$ concentration) linear least square regression analysis were obtained by peak area ratio of S-amlodipine (Figure 7) to its internal standard (Tizanidine) (Figure 8). The concentration of S-amlodipine in plasma samples were calculated using linear regression parameters by corresponding calibration curve.

\section{Results and Discussion}

\section{Chromatography}

Representative chromatograms containing solvent reference mix solution, blank plasma (Figure 9), blank plasma with internal standard

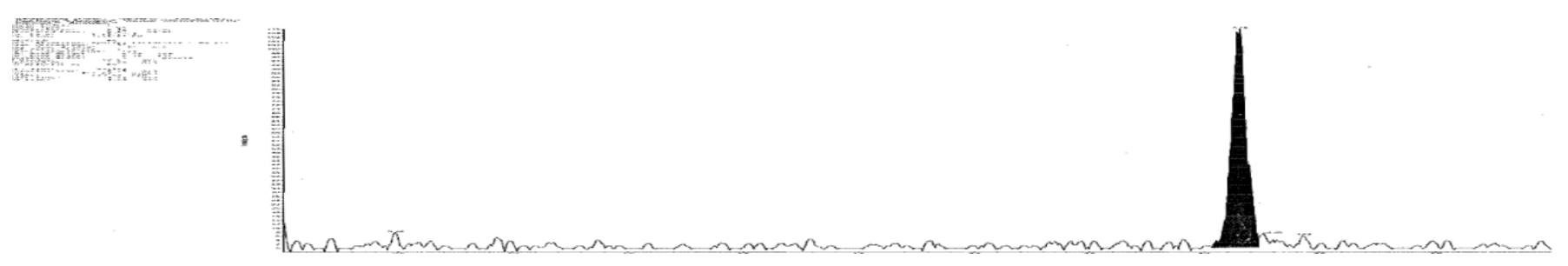

Figure 3: Chromatogram of LLOQ for S-amlodipine.

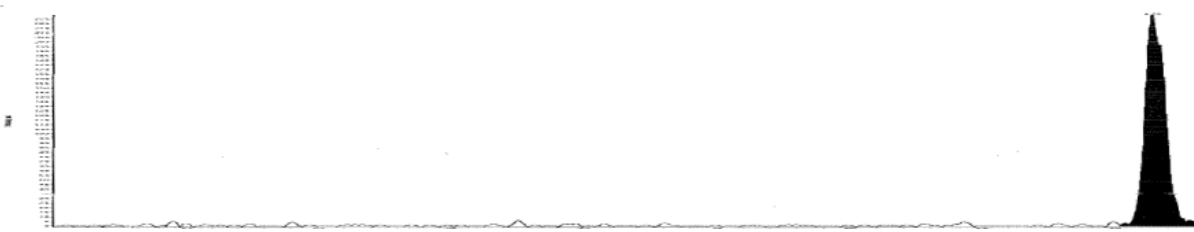

Figure 4: Chromatogram of LQC for S-amlodipine. 


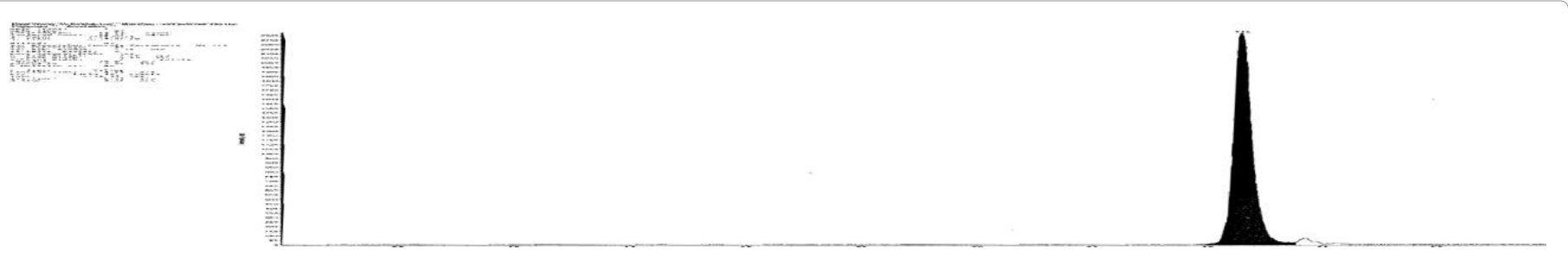

Figure 5: Chromatogram of MQC for S-amlodipine.
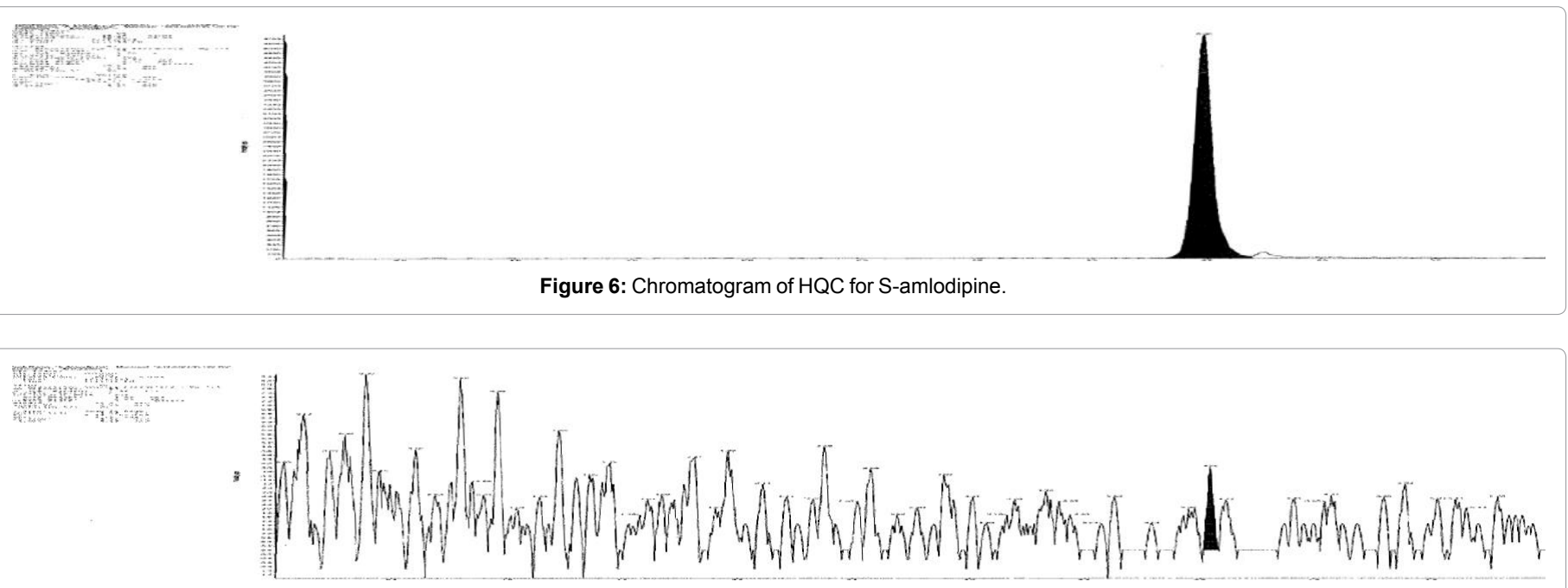

Figure 7: Chromatogram of blank plasma sample.

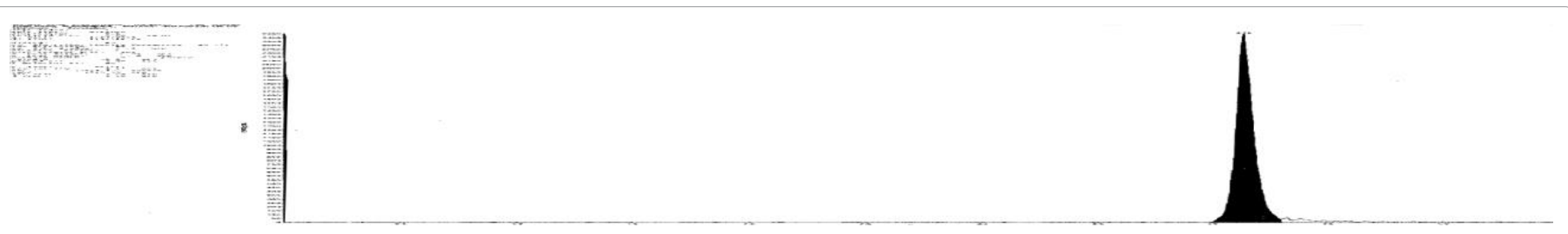

Figure 8: Chromatogram of an aqueous sample of S-amlodipine.

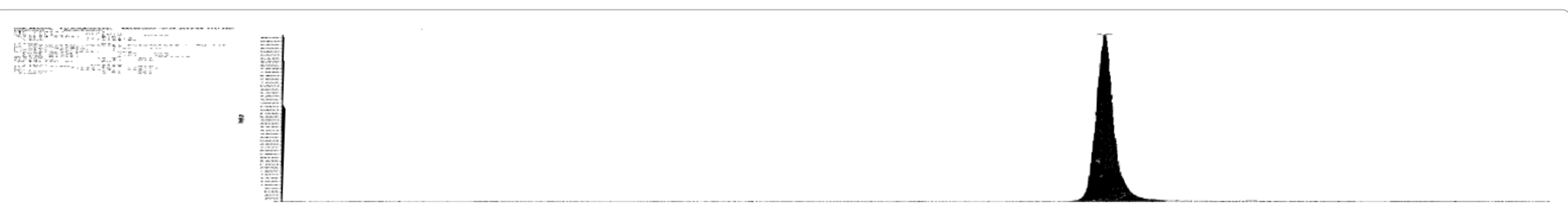

Figure 9: Chromatogram of an Inernal Standard (Tizanidine).

and quality control samples (LLOQ, LQC, MQC and HQC) and a calibration curve of representative regression analysis for $\mathrm{S}$-amlodipine.

\section{Selectivity}

Six lots of plasma with CPD anticoagulant were evaluated and none showed significant interfering peaks at the retention time of S-amlodipine and internal standard (Tizanidine).

\section{Linearity}

The linearity of S-amlodipine was determined by weighted least square regression analysis of standard plot associated with eight point standard curve. The calibration was shown to be linear from $0.77 \mathrm{ng} / \mathrm{ml}$ to $50.98 \mathrm{ng} / \mathrm{ml}$ for S-amlodipine (Figure 10). Best-fit calibration lines of chromatographic response versus concentration were determined by weighted least square regression analysis with weighting factor of $1 /$ concentration. The coefficient of correlation $\left(r^{2}\right)$ was consistently greater than or equal to 0.99 during the course of validation, which are within limits.

\section{Sensitivity}

The Limit of Quantitation was $0.79 \mathrm{ng} / \mathrm{ml}$ for S-amlodipine. The between batch precision and accuracy at LLOQ concentration for S-amlodipine using internal standard ratio method was $6.0 \%$ and $106.9 \%$ respectively. 


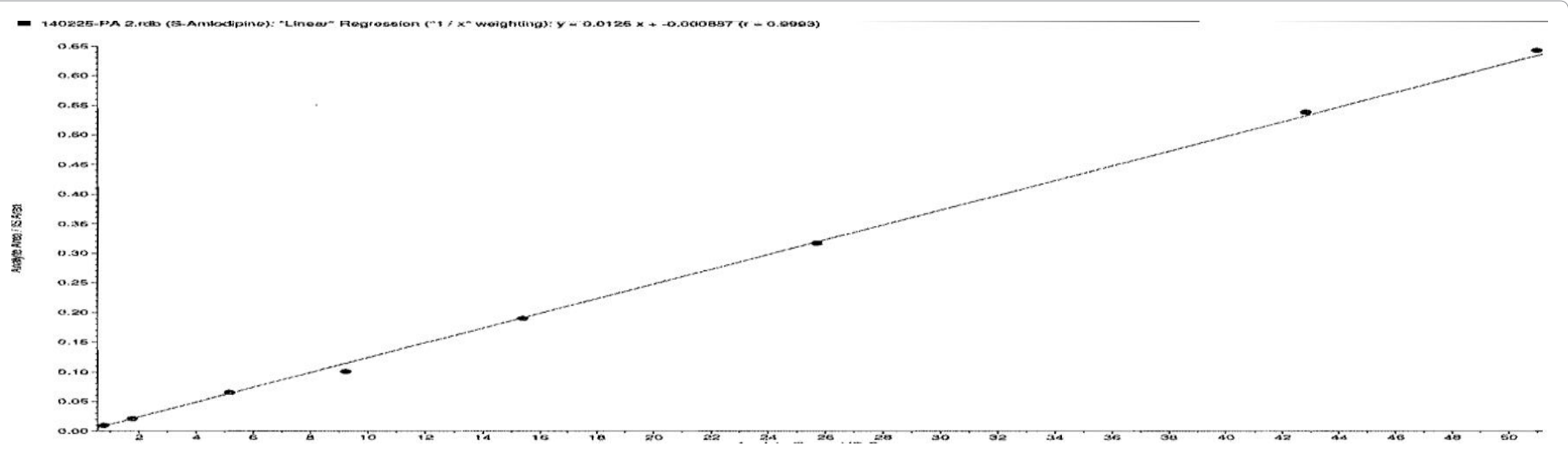

Figure 10: Regression analysis of calibration curve.

\section{Accuracy}

The accuracy of the assay was defined as the absolute value of calculated mean values of the quality control samples to their respective nominal values, expressed as percentage.

\section{Within batch accuracy}

The within batch accuracy using internal standard area ratio method ranged from $103.0 \%$ to $111.7 \%$ for S-amlodipine, which are within limits (Table 1).

\section{Between batch accuracy}

The between batch accuracy using internal standard area ratio method ranged from $106.6 \%$ to $110.5 \%$ for S-amlodipine, which are within limits (Table 1).

\section{Precision}

The precision of the assay was measured by the percent coefficient of variation over the concentration range of LLOQ, LQC, MQC and HQC quality control samples of S-amlodipine.

\section{Within Batch Precision}

The within batch precision using internal standard area ratio method ranged from $1.5 \%$ to $6.2 \%$ for S-amlodipine, which are within limits (Table 1).

\section{Between batch precision}

Between batch precision using internal standard area ratio method ranged from $2.1 \%$ to $6.0 \%$ for S-amlodipine which is within limits (Table 1).

\section{Recovery of analyte}

The percentage recovery of S-amlodipine was determined by

\begin{tabular}{|c|c|c|c|}
\hline S. No & Parameters & Acceptance Criteria & Results (\%) \\
\hline 1 & Within Batch Accuracy & $\begin{array}{c}\text { Nominal concentration: } \\
85-115 \%\end{array}$ & $103-111.7$ \\
\hline 2 & Between Batch Accuracy & $\begin{array}{c}\text { Nominal concentration: } \\
85-115 \%\end{array}$ & $106.6-110.5$ \\
\hline 3 & Within Batch Precision & $\%$ CV: $15 \%$ & $1.5-6.2$ \\
\hline 4 & Between Batch Precision & $\%$ CV: $15 \%$ & $2.1-6.0$ \\
\hline 5 & Recovery of Analyte & $\%$ CV: $20 \%$ & 0.7 \\
\hline 6 & Recovery of internal standard & $\%$ CV: $20 \%$ & 3.3 \\
\hline
\end{tabular}

Table 1: Results of accuracy, precision and recovery. measuring the peak area response of spiked (extracted) quality control samples (LQC, MQC and HQC) against the peak area response of aqueous (Unextracted) quality control samples (LQC, MQC and HQC) of equivalent concentrations. The percent recovery of S-amlodipine at LQC, MQC and HQC quality control samples were $98.41 \%, 97.22 \%$, $98.42 \%$ respectively. The \% CV for recovery of inter quality control samples for $\mathrm{S}$-amlodipine was $0.7 \%$, which is within limits. The $\%$ mean of recovery was $96.1 \%$, which are within limits (Table 1 ).

\section{Recovery of internal standard}

The percentage recovery of Tizanidine (IS) was determined by measuring the peak area response of spiked (extracted) quality control samples (MQC) against the peak area response of aqueous (unextracted) IS dilution of same concentration. The \% mean recovery and $\%$ CV for recovery of Tizanidine (IS) were $99.65 \%$ and $3.3 \%$, which are within limits (Table 1).

\section{Stability}

Freeze thaw stability: The stability of the spiked plasma samples was determined during three freeze-thaw cycles. Four replicates numbers of LQC and MQC samples (Stability samples) kept at $80^{\circ} \mathrm{C}$ and were analysed after third freeze thaw cycle against freshly spiked calibration curve standards and freshly spiked QC samples (comparison samples) .The comparative stability ranged from $98.6 \%$ to $99.9 \%$ for S-amlodipine, which are within limits (Table 2).

Bench top stability: The bench top stability (short term stability in matrix) determined by analyzing four replicates of low and high QC stability samples, which had been kept at room temperature for a designed time against the freshly spiked QC samples(comparison samples). The comparative stability ranged from $100.8 \%$ to $102.3 \%$ for S-amlodipine, which are within limits (Table 2).

Auto sampler stability: The auto sampler stability (post-processing stability) determined by analyzing four replicates of low and high QC stability samples, which had been processed and kept in auto sampler and were analyzed after against freshly spiked calibration curve standards and freshly spiked QC samples (comparison samples). The comparative stability ranged from $102.10 \%$ to $102.3 \%$ for S-amlodipine, which are within limits (Table 2).

Long term stability: For long term stability (long term stability in matrix) four replicates of low and high QC stability samples were analyzed against freshly spiked calibration curve. The low and high QC samples were stored for 04 days in deep freezer (at below $-20^{\circ} \mathrm{C}$ ) with 


\begin{tabular}{|c|c|c|c|}
\hline S. No & Parameters & Acceptance Criteria & Results (\%) \\
\hline 1 & Freeze and thaw cycle at $-80^{\circ} \mathrm{C}$ & $\begin{array}{c}\text { Mean } \% \text { change after } 3 \text { cycles } \\
\pm 15 \%\end{array}$ & $98.6-99.9$ \\
\hline 2 & Bench top stability & $\begin{array}{c}\text { Mean } \% \text { change after } 10.14 \mathrm{~h} \\
\pm 15 \%\end{array}$ & $100.8-102.3$ \\
\hline 3 & Auto sampler stability & $\begin{array}{l}\text { Mean } \% \text { change after } 50.04 \mathrm{~h}: \\
85-115 \%\end{array}$ & $102.10-102.3$ \\
\hline 4 & Long term Stability & $\begin{array}{c}\text { Mean } \% \text { change after } 7 \text { Days: } \\
\pm 15 \%\end{array}$ & $99.1-101.3$ \\
\hline 5 & Stock solution stability at room temp. & $\%$ Nominal concentration: $\quad \pm 15 \%$ & 97.5 (Analyte) 103.3 (IS) \\
\hline 6 & Dilution integrity & $\begin{array}{c}\text { Accuracy }(\% \text { Nominal }) \text { : } \\
\quad \pm 15 \% \\
\text { Precision( } \% \text { CV }): \leq 15 \%\end{array}$ & $\begin{array}{c}101.2 \\
4.0\end{array}$ \\
\hline 7 & Matrix effect & $\% \mathrm{CV} \leq 15 \%$ & $\begin{array}{l}\text { LQC } 9.35 \\
\text { HQC } 6.84\end{array}$ \\
\hline 8 & Ruggedness & $\begin{array}{l}\% \text { Nominal: } \pm 15 \% \\
\% \mathrm{CV}: \leq 15 \%\end{array}$ & $\begin{array}{c}107.1-111.4 \\
1.8-4.7\end{array}$ \\
\hline
\end{tabular}

Table 2: Result of stability, dilution integrity, matrix effect and ruggedness.

$\mathrm{CPD}$ as an anticoagulant in polypropylene tubes. The stability ranged from $99.1 \%$ to $101.3 \%$, which are within limits (Table 2).

\section{Stock solution stability at room temperature}

Stock solution stability at room temperature was performed by storing S-amlodipine and internal standard (Tizanidine) stock solutions at room temperature. The evaluation of stability was done by assaying six replicate injections of appropriately prepared dilutions of stored stock aliquot solutions of S-amlodipine and internal standard (Tizanidine) against six replicate injection of appropriately prepared dilution from fresh stock solutions of S-amlodipine and internal standard (Tizanidine) .The stock solution of S-amlodipine and internal standard (Tizanidine) was found to be stable, when stored at room temperature. The percent stability of the stock solution stability was 97.5\% and $103.3 \%$ respectively, which are within limits (Table 2).

\section{Dilution integrity}

Dilution Integrity was determined by assaying four replicates QCs spiked approximately two times the concentration of ULOQ. Samples were diluted by an appropriate factor (two) prior to extraction, against freshly spiked calibration standard samples. The accuracy for two times diluted concentration was $101.9 \%$ and four times diluted concentration were $101.2 \%$ for S-amlodipine .The precision for two times diluted concentration were $4.0 \%$ and four times diluted concentration were $2.8 \%$ for S-amlodipine, which are within limits (Table 2).

\section{Matrix effect}

Matrix effect was calculated by spiking analyte and IS at LQC and HQC levels into each of blank plasma extracts from six different batches of matrix respectively and analyzed in duplicate against six replicate injections of aqueous samples at low and high QCs samples. At low and QCs samples, the $\%$ coefficient of variation for matrix factor was found to be $9.35 \%$ and $6.84 \%$, respectively for S-amlodipine which is within limits (Table 2).

\section{Ruggedness}

The ruggedness of the extraction procedure and chromatographic method was evaluated by analysis of a batch of six sets of quality control samples and a set of calibration standards using different column (same type) by another analyst. The within batch accuracy ranged from $107.1 \%$ to $111.4 \%$ and within batch precision ranged from $1.8 \%$ to $4.7 \%$ for S-amlodipine .The results indicated that the batch met the acceptance criteria of linearity, precision and accuracy data of the quality control samples, which are within limits (Table 2).

\section{Stock solution stability at refrigerated temperature (4.0 days)}

Stock solution stability at refrigerated temperature was performed by $\mathrm{S}$-amlodipine and internal standard (Tizanidine) stock solutions at refrigerated temperature. The evaluation of stability was done by assaying six replicates injections of appropriately prepared dilution from stored aliquot solutions of S-amlodipine and internal standard (Tizanidine) against six replicate injection of appropriately prepared dilution from fresh stock solutions of S-amlodipine and internal standard (Tizanidine). The percent stability of the stock solution for S-amlodipine and internal standard (Tizanidine) were $101.3 .0 \%$ and $101.5 \%$ respectively which are within limits.

\section{Conclusion}

The above analytical method described is valid the determination of S-amlodipine (over a range of $0.77 \mathrm{ng} / \mathrm{ml}$ to $50.98 \mathrm{ng} / \mathrm{ml}$ ) using Tizanidine as internal standard in human plasma using a Phenomenex, Lux $3 \mathrm{u}$ Cellulose, $(150 \times 4.6) \mathrm{mm}$ column.

\section{Acknowledgement}

The authors are thankful to Management, for providing the research grant. The authors report no conflicts of interest. The authors alone are responsible for the content and writing of the paper. I avail this opportunity, with great pleasure and deep sense of gratitude, to express my thanks to my research fellows and especially Mr. Sunil for providing enough patience, zeal and strength that enabled me to complete this work successfully.

\section{References}

1. Monkman SC, Ellis JS, Cholerton S, Thomason JM, Seymour RA, et al. (1996) Automated gas chromatographic assay for amlodipine in plasma and gingival crevicular fluid. J Chromatogr B Biomed Appl 678: 360-364.

2. Chitlange SS, Kiran Bagri, Sakarkar DM (2008a) Stability Indicating RP- HPLC Method for Simultaneous Estimation of Valsartan and Amlodipine in Capsule Formulation. Asian J Research Chem 1: 15-18.

3. Shah DA, Bhatt KK, Mehta RS, Baldania SL, Gandhi TR (2008) Stability indicating RP-HPLC estimation of atorvastatin calcium and amlodipine besylate in pharmaceutical formulations. Indian J Pharm Sci 70: 754-60.

4. Chitlange SS, Mohammed I, Dinesh MS (2008b) RP-HPLC method fo simultaneous estimation of amlodipine and metoprolol in tablet formulation. Asian Journal of Pharmaceutics 2: 232-234.

5. Sarkar Ak, Ghosh D, Das A, Selvan PS, Gowda KV, et al. (2008) Simultaneous determination of metoprolol succinate and amlodipine besylate in human plasma by liquid chromatography-tandem mass spectrometry method and its application in bioequivalence study. J of Chromatogr B Analyt Technol Biomed Life Sci 873: 77-85. 
Citation: Dhiman R, Durga V, Meetei KH (2015) Determination of S-amlodipine in Human Plasma Using Tizanidine as Internal Standard by Lc/Ms/Ms Method. J Bioanal Biomed 7: 091-096. doi:10.4172/1948-593X.1000130

6. Rohatagi S, Lee J, Shenouda M, Haworth S, Bathala MS, et al. (2008) Pharmacokinetics of amlodipine and olmesartan after administration of amlodipine besylate and olmesartan medoxomil in separate dosage forms and as a fixed-dose combination. J Clin Pharmacol 48: 1309-1322.

7. Norvasc (2008) The Internet Drug Index. RxList Inc.

8. Abernethy DR (1989) The pharmacokinetic profile of amlodipine. Am Heart $J$ 118: 1100-1103.

9. ICh (2001) ICH harmonized tripartite guideline: Guideline for Good Clinical Practice. J Postgrad Med 47: 45-50.

10. Suchanova B, Kostiainen R, Ketola RA (2008) Characterization of the in vitro metabolic profile of amlodipine in rat using liquid chromatography-mass spectrometry. Eur J Pharm Sci 33: 91-99.
11. Douglas AS, James HF, Donald MW (1996) Fundamentals of Analytical chemistry. Saunders College Publisher, Philadelphia 7: 1-15.

12. Kungys G, Naujoks H, Wanner C (2003) Pharmacokinetics of amlodipine in hypertensive patients undergoing haemodialysis. Eur J Clin Pharmacol 59: 291-295.

13. http://www.drugbank.ca/drugs/db00381

14. http://www.drugbank.ca/drugs/db00697

15. Reid JL, Meredith PA, Donnelly R, Elliott HL (1988) Pharmacokinetics of calcium antagonists. J Cardiovasc Pharmacol 12 Suppl 7: S22-26.

16. Snyder LR, Kirkland JJ, Glajch JL (1997) Practical HPLC method development (2ndedn.) John Wiley and Sons, pp. 1-14. 